\title{
La Ética de Adam Smith: Conciliando \\ Paradigmas, una Propuesta Olvidada
}

\author{
María Alejandra Carrasco ${ }^{I}$
}

\begin{abstract}
RESUMEN: En su Teoría de los Sentimientos Morales Adam Smith propone una ética que concilia dos paradigmas habitualmente considerados como incompatibles: una ética de virtudes, con normas orientativas e ideales de excelencia, y una ética con reglas universales que se aplican en todos los casos sin excepción. Smith lo hace cambiando el punto de vista desde el que se realiza el juicio moral, a una perspectiva que llamaré "simpatético-imparcial", y que corresponde a "los sentimientos simpatéticos de un espectador imparcial y bien informado". Este novedoso punto de vista le permite introducir características modernas a la ética clásica de la virtud para dar una nueva justificación a las virtudes positivas, así como cambiar el modo de entender las "reglas o principios universales". De este modo, Smith construye una ética capaz de dar cuenta, dentro del mismo marco teórico, tanto de los ideales de excelencia propios de la virtud, como de los imperativos universales modernos.
\end{abstract}

PALABRAS CLAVE: Adam Smith. Ética. Virtudes. Justicia. Universalidad.

En su provocativo ensayo acerca de la filosofía moral moderna, G.E.M. Anscombe afirma: "Si alguien expone a Aristóteles y habla de moral en sentido moderno, debe ser muy poco perceptivo si no siente como si sus mandíbulas se hubieran desencajado y sus dientes no se ajustan para una correcta mordida." (ANSCOMBE, 1958, p. 2). Muchos pensadores, antes y después de ella, comparten el mismo diagnóstico: Existiría una inconmensurabilidad entre el paradigma moral clásico y el moderno.2 Anscombe explica que la ética clásica no busca cánones ni reglas universalmente vinculantes como hacen los modernos, sino que la virtud se determina en "cada caso particular, 'de acuerdo con lo más razonable’, pero eso, obviamente, no es un canon.” (ANSCOMBE,

\footnotetext{
${ }^{1}$ Profesora Asociada del Instituto de Filosofía de la Pontificia Universidad Católica de Chile. Mis agradecimientos al proyecto Fondecyt 1141208, así como al Centre for the Study of Mind and Nature (CSMN), de la Universidad de Oslo, por su acogida durante una estadía de investigación. E-mail: mcarrasr@uc.cl.
}

http://dx.doi.org/10.1590/S0101-31732016000300003

${ }^{2}$ Para una exposición histórica del quiebre entre estos dos paradigmas ver Irwin, 2007, cap. 32. 
1958, p. 2). ${ }^{3}$ Christine Korsgaard (1996, p. 4) también contrasta la ética de las disposiciones antigua que aspira al logro de la excelencia humana, con la ética de principios moderna que se centra en obligaciones que no se pueden violar sin merecer castigo. De ahí la incompatibilidad de estos sistemas: difieren en sus fines, objetos y modos de deliberación. La idea de leyes universales y válidas en todos los casos, característica de los sistemas modernos, no cabe en la ética de las virtudes. Los juicios de la última dependen del contexto, evalúan las disposiciones del carácter del agente según su situación concreta. Esta ética tampoco se construye sobre principios universales que tracen un límite entre el bien y el mal, ni ofrece un catálogo de reglas precisas, válidas y obligatorias para todo ser humano de cualquier tiempo o lugar. ${ }^{4}$

Doscientos años antes de que Anscombe planteara su singular metáfora, Adam Smith, en La Teoría de los Sentimientos Morales (TMS), también había apuntado a este hecho acusando de reduccionismo metodológico tanto a moralistas antiguos como a los modernos, que no distinguen entre clases de virtudes ni en la precisión que sus respectivas normas admiten. Unos dan cuenta de normas generales y orientativas, propias de las virtudes positivas; mientras los otros se empeñan en introducir en toda la ética los preceptos rígidos y exactos que solo corresponden a la justicia (TMS VII.iv.2). ${ }^{5}$ Y esta falta de distinciones impediría a ambos sistemas proponer teorías plausibles para explicar todas las variantes de la conducta moral humana.

No obstante, a diferencia del rechazo de Anscombe a las éticas de reglas, en este artículo postularé -siguiendo la metáfora "odontológica" de Anscombeque Smith cree que una buena mordida necesita de las dos mandíbulas; es decir, una teoría moral debe dar cuenta tanto de las virtudes positivas con su aspiración a la excelencia y el juicio de propiedad de las pasiones/acciones en cada situación particular; como también de la justicia con leyes universalmente vinculantes y obligatorias. Naturalmente los maxilares deben alinearse. Para ello, Smith

\footnotetext{
${ }^{3}$ Su análisis se centra en la ética aristotélica. Contrasta la "ética de reglas" moderna que juzga casos particulares aplicando "principios prácticos supremos" con independencia de las circunstancias, con la ética de las virtudes antigua que aparte de orientaciones generales, los juicios de casos particulares "[...] deben muchas veces hacerse $[\ldots]$ solo por vía de ejemplos".

${ }^{4} \mathrm{La}$ voz "universal" se define como "[q]ue comprende o es común a todos los de su especie, sin excepción de ninguno", y una "ley universal" es "[l]a que es válida cualquiera que sea la naturaleza de los cuerpos a los que se aplica” (Diccionario de la Real Academia Española). De acuerdo con FLEW (1984, p. 360), "[...] un universal es una propiedad que se predica de todos los individuos de cierta clase"; “ "[...] si admitimos que los juicios morales particulares se vinculan a reglas universales, se evita el riesgo de la arbitrariedad en las decisiones respecto de los individuos concretos".

${ }^{5}$ Cito a Smith de la manera canónica, vale decir: Parte/Sección (cuando procede)/Capítulo/Parágrafo.
} 
propone un tercer paradigma capaz de justificar simultáneamente las virtudes dependientes del contexto y las reglas universales de justicia. Lo hace cambiando la perspectiva desde la que se realiza el juicio moral a una perspectiva que llamaré "simpatético-imparcial", y que corresponde "a los sentimientos simpatéticos de un espectador imparcial y bien informado" (TMS.ii.1.49). Estos serían los sentimientos morales. Este novedoso punto de vista le permite introducir características modernas a la ética clásica de la virtud para dar una nueva justificación a las virtudes positivas; así como cambiar la manera de entender las "reglas o principios universales", que durante la Modernidad se identificaron con principios trascendentes o a priori, fuera del espacio y del tiempo. Con estas modificaciones, Smith construye una ética capaz de dar cuenta dentro del mismo marco teórico tanto de los ideales de excelencia propios de la ética de la virtud, como de los imperativos universales modernos.

Para mostrar cómo articula estos elementos comenzaré exponiendo las tendencias psicológicas innatas de las que emerge la conciencia moral con su perspectiva simpatético-imparcial, la que es crucial para la justificación moderna de las virtudes positivas. Esta será la primera "mandíbula". La segunda será cómo, dentro de esta misma teoría, Smith da cuenta de la autoridad universal de las reglas de justicia. Finalmente, explicaré la "alineación de los dientes", o cómo la perspectiva simpatético-imparcial introduce la noción moderna de imparcialidad como el estándar común y racionalmente justificable de todas las virtudes, así como una -según llamaré- "universalidad fáctica” para un reducido grupo de reglas morales. Con estos dos instrumentos Smith superaría las insuficiencias de los otros dos paradigmas morales, proponiendo un modelo comprehensivo que capturaría las intuiciones básicas de ambos.

\section{I ÉTICA MODERNA DE LAS VIRTUDES}

Smith se auto-identifica con la tradición de la ética de la virtud, entendiendo por virtud un hábito operativo que consiste en un término medio determinado por la recta razón (TMS VII.ii.1.12). Sin embargo, critica a los clásicos por no proponer una medida precisa para establecer la propiedad de un afecto/acción en cada situación particular. Esa medida, afirma, se encuentra en los sentimientos simpatéticos de un espectador imparcial bien informado. Con esto Smith se jacta de superar las deficiencias de la ética clásica proveyendo un estándar común, al estilo moderno, para justificar los juicios que dependen del contexto. 
Como filósofo empirista, Smith explica el surgimiento de este estándar "desde abajo" (FRICKE, 2013, p. 17), ${ }^{6}$ es decir, constatando algunas tendencias psicológicas humanas desde las que se desarrollará la conciencia moral. Destaca el deseo de simpatía mutua o de aprobar y sentirse aprobado por los demás. Para ello, cuando interactuamos nos "cambiamos de lugar" con el otro para captar, cuanto sea posible, sus sentimientos en esta situación particular, y moderar así los nuestros hasta un punto que el otro pueda aceptar (TMS I.i.4.8). Este punto de coincidencia será el punto de propiedad, y corresponde a la respuesta afectiva que ambos actores consideran adecuada para una situación dada (TMS I.i.3.9). Entonces, en esta primera descripción, la propiedad se encuentra entre actores concretos, socialmente situados, que alcanzan la coincidencia en un esfuerzo conjunto tras un proceso de identificación simpatética. En este nivel psicológico la propiedad es consensual; pero es también la base para el desarrollo de la conciencia moral.

\section{De la PSicología a la Moral}

El proceso simpatético revela una demanda de respeto mutuo. En sociedad la gente se relaciona desde lo que Stephen Darwall (2006, p. 122) llama la perspectiva de la segunda persona o relaciones yo-tú, en las que recíprocamente nos demandamos respeto de reconocimiento. P. F. Strawson (1974, p. 16) da un paso más diciendo que, en su nivel más básico, la moral es un sistema de demandas y expectativas entre agentes que se reconocen como igualmente responsables. Naturalmente solo participamos en relaciones yo-tú con quienes consideramos capaces de corresponder al mismo respeto que nosotros les brindamos, o a quienes consideramos nuestros iguales. Análogamente, en Smith el deseo innato de simpatía mutua sería el humus desde el que esta dimensión moral emerge. En el proceso simpatético yo ya exijo respeto para mí; pero en la esfera moral, según describe Strawson (1974, p. 15), esta demanda se generaliza y se exige respeto para todos nuestros iguales. Lo mismo sucederá en el desarrollo de la conciencia moral tal como lo describe Smith.

En la TMS los juicios morales dependen de los mismos procesos simpatéticos que se dan en el nivel psicológico. Smith lo explica al describir la formación natural de la conciencia moral, ilustrada como el "espectador

\footnotetext{
${ }^{6} \mathrm{El}$ "desde abajo" es particularmente importante en la actualidad, precisamente por su diferencia con las éticas de principios modernas.
} 
imparcial dentro del pecho". ${ }^{7}$ Señala que mientras permanecemos en nuestra familia es fácil obtener el placer de la simpatía mutua. Pero cuando salimos al mundo y nos enfrentamos con espectadores indiferentes, sentimos por primera vez la desaprobación de nuestros afectos parciales y nos esforzamos por superarla a través del proceso simpatético. Entonces "salimos de nosotros mismos" para situarnos en la perspectiva del otro y vernos a través de su mirada, descubriendo que no somos más que uno en una multitud de iguales (TMS II.ii.2.1), y que si no restringimos nuestras pasiones desmesuradas, nunca obtendremos su simpatía. Este es el punto crucial para el surgimiento de la conciencia. La sociedad proporciona esos espejos que requerimos para aprender a relacionarnos como iguales y desarrollar sentimientos morales.

Comenzamos imaginando un espectador equidistante entre nosotros y el otro, e intentamos comportarnos como creemos que ese espectador aprobaría. Sin embargo, como cada persona es diferente y es imposible agradar a todos, aprendemos a imaginar un espectador imparcial, "un hombre en general” (TMS III.2.31), y actuar según su criterio. Esta es la puerta de entrada a la esfera moral, pues nos damos cuenta de que todos somos iguales y merecemos igual respeto.

Sentir y actuar virtuosamente, para Smith, implica ajustar nuestros sentimientos a los de un espectador imparcial. Para lograrlo debemos pasar por la "gran escuela del self-command" (TMS III.3.22), donde aprendemos nuevas formas de deliberación, adquirimos nuevos hábitos y aprendemos a moderar nuestros afectos egoístas para, por así decir, "im-parcializarlos" o identificarlos con los de cualquier espectador imparcial. Nuestros sentimientos de primer orden son modelados por "nuestros principios activos" (TMS III.3.4) para dar lugar a sentimientos de segundo orden; los que siguen siendo nuestros pero ahora mediados por "la razón, el principio, la conciencia", esto es, sentimientos morales. Las pasiones innatas se redirigen al objeto específico que hemos elegido y aprobado conscientemente.

Por tanto, a pesar de que la primera motivación para actuar imparcialmente es el placer de la simpatía, en el curso del desarrollo moral aprendemos a orientar nuestros sentimientos a bienes distintos de nuestra propia satisfacción. Aunque el espectador en Smith se origina en la interacción,

\footnotetext{
${ }^{7}$ Smith los identifica: "Es la razón, el principio, la conciencia, el habitante del pecho [...]" (TMS III.3.4). Forman-Barzilai (2010, p. 156) lo ratifica: "Smith nos presenta al espectador imparcial, una facultad similar a la conciencia que todos tenemos, y que asegura que nuestros sentimientos pasivos no nos impulsarán a realizar juicios y acciones excesivamente parciales."
} 
trasciende la dimensión social para proporcionar una perspectiva crítica y simpatética a la vez (GRISWOLD, 2001, p. 165). De ahí la importancia de la distinción entre el deseo de alabanza y el deseo de ser digno de alabanza que hace Smith, puesto que establece una nueva concepción antropológica en el que el deseo del bien es tan natural para nosotros como el deseo de satisfacción subjetiva (TMS III.2.5).

En suma, enraizar la conciencia moral en la simpatía permite a Smith proponer una ética de disposiciones afectivas que contenga "la única y brillante idea de conectar el principio de imparcialidad con la correspondencia afectiva ... para hacer más accesibles las virtudes a la conciencia moderna” (TUGENDHAT, 2005, p. 102). Mi tesis es que lo logra por la novedosa perspectiva simpatético-imparcial desde la que se realiza el juicio. En los procesos simpatéticos morales "entramos en el otro" y juzgamos tal como lo haría un espectador imparcial, es decir, poniendo entre paréntesis nuestros propios sesgos y parcialidades (DARWALL, 1999, p. 142). De este modo, el punto de propiedad moral, o la actitud virtuosa, será la reacción afectiva que un espectador imparcial aprobaría en un contexto concreto. La diferencia entre el proceso simpatético psicológico y el moral es que en el primero el ajuste afectivo se realiza entre dos personas reales, y en el otro se hace según un criterio preciso: los sentimientos de un espectador imparcial. Estos sentimientos ya informados por la imparcialidad, los sentimientos morales, determinan la virtud. La aparición del espectador imparcial cambia la motivación y la justificación del proceso simpatético. En lugar del placer subjetivo de sentirse aprobado, la motivación es el deseo de ser "digno de aprobación", el amor a la virtud (TMS VII.ii.4.8). Y su justificación es nuestra igualdad expresada en el igual respeto que todos nos debemos.

\section{UN “CANON"}

En la ética aristotélica la virtud se determina de acuerdo con la recta razón o tal como lo haría un hombre prudente. El juicio, en que co-operan razón y sentimientos, considera las circunstancias particulares de cada caso. La recta razón no es una fuente de normatividad externa a la comunidad moral ni provee normas universales para evaluar indiscriminadamente en todos los casos. Por eso, como dice Anscombe, no se puede considerar un "canon".

Los juicios morales en Smith también tienen estas características, excepto que él sustituye la "idea vaga" de recta razón por la "medida precisa" del juicio 
de un espectador imparcial. Los juicios del espectador proporcionan un punto de vista general y válido para todos los agentes razonables (GRISWOLD, 2001, p. 163). Este espectador, con su perspectiva simpatético-imparcial, es el elemento que Smith introduce para garantizar los juicios morales imparciales, à la moderne, dentro de su ética de la virtud.

Esta perspectiva permite, como en Aristóteles, aprehender la realidad afectiva y cognitivamente a la vez. La simpatía conserva la apertura al contexto propia de la ética de la virtud pues implica la identificación del espectador con los sentimientos y la situación del agente. Pero también vincula el juicio moral al deseo de simpatía mutua, haciéndolo depender de la interacción. Y es esta última la que engendra la conciencia moral y la sigue formando toda la vida. En la TMS las personas deben estar siempre confrontando, corrigiendo y refinando sus juicios mediante procesos simpatéticos. Para Smith la formación de la conciencia es una co-formación; no cree en sabios ni hombres prudentes que con su propia e incomunicable recta razón puedan determinar lo que es virtuoso en cada caso. La virtud se determina en un esfuerzo conjunto donde todos renuncian a su centralidad para capturar lo que una situación verdaderamente merece; son "sentimientos avalados por los aspectos de la situación al que responden” (DARWALL, 1997, p. 268), que todos reconocen como "la respuesta emocional correcta" (FLEISCHACKER, 2013, p. 302). Además, el carácter interactivo de los juicios también lleva a los agentes a descubrir su igualdad y el recíproco deber de respeto. La imparcialidad, entonces, no es un criterio consensuado ni impuesto desde fuera y justificado a priori. El criterio moral se descubre en los propios sentimientos naturales y se valida con la experiencia.

Esta imparcialidad, en cuanto simpatética, debe garantizarse por una doble adecuación. Primero, el agente con el objeto. Los juicios de propiedad se refieren a la proporcionalidad de la reacción afectiva del agente con la situación que vive. Este paso es análogo al de la ética clásica. Pero Smith requiere de una segunda adecuación para sentenciar la propiedad, a saber, el ajuste o correspondencia de sentimientos entre el agente y el espectador imparcial. La mediación de esta tercera instancia (el espectador imaginario) es el elemento intersubjetivo que durante la Ilustración Escocesa se validó como fuente legítima de objetividad moral. Ella cumple el papel fundamental de inducir a los individuos a distanciarse de sus intereses particulares y evaluar objetivamente la adecuación del agente y sus circunstancias. Por consiguiente, la imparcialidad en Smith implica una doble adecuación: agente- 
circunstancias y agente-espectador imparcial. Este proceso proporcionaría una "medida precisa" para determinar la virtud, o la sustitución de la antigua recta razón por un estándar legítimo para la mentalidad moderna. A esto se refiere Tugendhat (2005, p. 99) cuando afirma que, con la introducción del espectador imparcial, "[...] el 'justo medio' aristotélico recibe un contenido y una determinación pública”, o un estándar común y racionalmente justificable para establecer la corrección moral. Un canon.

\section{JUSTICIA Y UNIVERSALIDAD}

El estándar común para justificar las virtudes positivas constituiría -en la metáfora de Anscombe - el primer maxilar en la TMS. El segundo es dar cuenta de las reglas de justicia. La ética de la virtud propone orientaciones generales para alcanzar la excelencia; virtudes positivas, que no se pueden imponer y cuya violación no merece castigo. Pero también existe la virtud negativa de la justicia, que según Smith exige un tratamiento distinto puesto que sus normas expresan obligaciones que sí se pueden subsumir en reglas precisas y obligatorias, de validez y alcance universal (TMS.II.1.5).

Entonces, para que la TMS sea una ética verdaderamente comprehensiva, Smith debe justificar dentro del mismo marco teórico las normas orientativas de las virtudes positivas y las normas precisas y universalmente vinculantes de la justicia. Eso implica describir a la justicia tanto como una virtud que depende del contexto, igual a todas las demás; como, también y al mismo tiempo, fuente de normas precisas, obligatorias, capaz de trazar una línea que separe lo moralmente permisible de lo prohibido.

\section{Peligro de relativismo}

La perspectiva simpatético-imparcial de la ética de Smith no alcanza para justificar la autoridad universal de las reglas de justicia. El elemento simpatético la hace depender del contexto, y por esa razón muchos autores se oponen a su pretensión de universalidad. Griswold, por ejemplo, afirma que si el espectador imparcial no busca normas que se auto-sustenten, independientes de la comunidad, nunca podrá escapar del espacio y el tiempo (2006, p. 184). Solo habría universalidad si el espectador se situara en un punto de vista externo al espectáculo humano, el que para Smith no existe (GRISWOLD, 1999, p. 258). 
Forman-Barzilai también dice que para que la TMS funcione la justicia tendría que estar fuera de la historia, lejos de las contingencias de la vida ordinaria. Según ella, Smith describe dos sistemas yuxtapuestos, una "moral ordinaria” para las virtudes positivas, que se origina en los procesos simpatéticos; y una "teoría de la justicia" totalmente independiente (FORMAN-BARZILAI, 2010, p. 219). Por eso pregunta: “¿De dónde se supone que Smith deriva los principios inmutables y universales de justicia, si la fuente de nuestros sentimientos morales es la interacción social?” (FORMAN-BARZILAI, 2010, p. 229). Si el espectador imparcial no es más que una conciencia socializada, sus estándares no pueden ser objetivos. Y añade “¿Cómo pudo Smith pretender universalidad sin abstraer la moral de sus raíces empíricas?” (FORMANBARZILAI, 2006, p. 100).

Mucha evidencia textual apoya su tesis de las dos teorías. Smith mismo reconoce que la virtud de la justicia es extraordinariamente distinta a las otras virtudes. Dice que las virtudes positivas son optativas y que no se castiga por no cumplirlas, mientras que la justicia es obligatoria y su violación merece castigo. Añade que nos sentimos interpelados de modo especial por ella (TMS II.ii.1.5); y que es un deber que se impone a todas las personas al margen de cualquier circunstancia. Las reglas de justicia son precisas, no admiten excepciones, son imperativas y separan lo permisible de lo inmoral. En contraste, las de las virtudes positivas "sugieren" pero no "mandan", son imprecisas y se adaptan al contexto.

No obstante, también hay elementos en la TMS que se oponen a la tesis de las dos teorías y permiten postular que Smith sí tiene los medios teóricos para articular estas dos clases de virtudes y normas. Por ejemplo, cuando describe los juicios de justicia lo hace en perfecto paralelo con los de beneficencia, dando incluso una única definición para ambos: "Remunerar, recompensar, devolver bien por bien [...] o mal por mal” (TMS II.i.1.4). También asimila su estructura: en estos juicios el espectador se enfrenta a dos actores y debe simpatizar con ambos. En los juicios de beneficencia se atribuye mérito al agente y se comparte la gratitud del favorecido; y en los de justicia se culpa al agente y se comparte el resentimiento de la víctima, al punto que el espectador siente como si la agresión le hubiese sido hecha a él. Los juicios de justicia y de beneficencia son como el cara y sello de la misma moneda. Ambos se fundan en procesos simpatéticos y se justifican por el igual respeto según establece el espectador imparcial. 
La gran diferencia entre estas virtudes es su expresión normativa, pero la expresión no se relaciona con el fundamento de los juicios. En la acción benéfica el agente da al otro más de lo debido, pero no se puede obligar a nadie a realizar este tipo de acciones: mientras el agente respete al otro como un igual, todo lo demás será opcional. En la acción injusta, en cambio, el agente agrede al otro, lo trata como un inferior. Es decir, le da menos del respeto debido. Y esto es lo que el espectador imparcial desaprueba y rechaza con la mayor vehemencia (TMS III.3.4), recordándonos que no somos más que uno en una multitud de iguales. La justicia no puede ser opcional. Si nos sentimos obligados por sus normas, si nos parecen imperativas, si su violación merece castigo, es por nuestra identificación simpatética con la víctima que no fue respetada como un igual. Las normas de justicia surgen de nuestros sentimientos morales al simpatizar con quien no fue respetado. "Las sagradas reglas de la justicia", como las llama Smith, no son a priori ni deducidas de algún principio. Ellas solo obedecen a nuestra naturaleza social, a la tendencia innata a la simpatía.

En suma, si tanto la expresión normativa como la fuerza vinculante de las reglas de justicia son tan distintas a las de las otras virtudes, es porque ellas salvaguardan el igual respeto de reconocimiento en el que se basa la interacción social. La justicia marca el límite entre lo moral y lo prohibido. Pero sus reglas surgen de los mismos procesos simpatéticos que los de cualquier norma moral. No existen dos teorías yuxtapuestas.

\section{IMPARCIALIDAD-SIMPATÉTICA Y UNIVERSALIDAD}

En la TMS la propiedad, o el "grado adecuado de cada pasión" (TMS I.ii.introd.2) se define desde la perspectiva simpatético-imparcial según las circunstancias del caso. Pero si depende tanto de lo empírico, como con razón afirman los intérpretes, ¿`cómo puede la justicia dar el salto a la universalidad?

Para comprender cómo es posible superar la oposición entre lo empírico y lo universal - entendiendo por "universal" lo que se aplica en todos los casos sin excepción y no como "un principio ahistórico, fuera de todo lugar" (GRISWOLD, 2006, p. 183) - el concepto de "importe" (TAYLOR, 1985, p. 48) es de gran ayuda. El importe expresa el aspecto de una situación al que reaccionamos afectivamente según el tipo de ser que somos. Los gatos, por ejemplo, pertenecen a una clase de seres que teme a los perros, por lo que todo gato huye cuando ve un perro. Nosotros también reaccionamos a importes. 
Algunos dependen de nuestra cultura y hay otros culturalmente neutros, i.e. producen la misma reacción en todo ser humano simplemente por el tipo de ser que es. Smith da un ejemplo al comenzar su libro diciendo que el miedo a la muerte es el mejor disuasivo contra la injusticia en la humanidad (TMS I.i.1.13). El ejemplo es interesante porque relaciona ya a la justicia con un importe que afecta a toda la humanidad.

Mi tesis es que la precisión de las reglas de justicia, a diferencia de otras virtudes, se debe al tipo de importe al que se reacciona. Generalmente, respecto de las virtudes positivas, el agente está respondiendo a importes relativos a la cultura. En estos casos el punto de propiedad variará según factores contingentes como la historia, el clima o las expectativas de cada sociedad (TMS III.3.21). Aquí no hay una única respuesta válida para todos. Pero la virtud de la justicia es distinta porque su importe es distinto. La injusticia, o dañar injustificadamente a un tercero (TMS II.ii.1.5) siempre produce resentimiento. En la interacción social la justicia marca el mínimo moral ya que es la virtud que salvaguarda algo tan básico como el igual respeto que nos debemos por el mero hecho de nuestra humanidad. Entonces, si todos reaccionamos igual frente a una agresión injustificada es porque en los juicios de justicia el único importe moralmente relevante, o el único aspecto de la situación que el espectador considera, es si la víctima es o no persona humana. El importe es culturalmente neutro: basta saber si el agredido es persona para reaccionar afectivamente contra el agresor. Todos sentimos el mismo resentimiento solo por el tipo de ser que somos; independientemente de nuestra cultura, mérito o circunstancias.

Por tanto, la expresión normativa de las reglas de justicia es distinta porque garantizan el respeto de reconocimiento que todos nos debemos y que es condición de la interacción social. Como garantiza la igualdad, no puede tener grados: o se respeta o no se respeta al otro como igual. En otras palabras, el "grado apropiado" es el mismo en cualquier cultura: es absoluto; un poco menos ya sería injusticia. Por eso estas reglas puedan ser precisas y válidas para todos, esto es, son fácticamente universales. ${ }^{8} \mathrm{Y}$ son negativas: Dicen lo que las personas no pueden hacer a otros porque no los respetarían. Así es como marcan el límite entre lo permisible y lo prohibido. Y si nos sentimos más obligados por ellas, dice Haakonssen (1981, p. 85-6), es porque las sentimos

\footnotetext{
${ }^{8}$ La autoridad de las reglas de justicia no depende de si son reconocidas por las personas; las personas pueden no obedecerlas, pero ni las perversiones ni la ceguera moral abrogan su autoridad universal.
} 
como una deuda: hay algo que debimos dar y no dimos. Este "algo", en mi interpretación, es justamente el respeto que el otro merece.

En consecuencia, a pesar de las diferencias, las reglas de justicia se originan y justifican igual que todas las virtudes. La justicia depende de la identificación simpatética, es relativa al contexto, pero la autoridad de sus reglas es, o al menos debería ser, la misma en todo tiempo y lugar. Y si una ética empirista admite reglas con pretensión de universalidad es porque la conducta que regulan responde a un importe culturalmente neutro: basta saber que la víctima es un ser humano. Cualquier otra información es trivial.

Por tanto, según lo dicho, las normas de justicia dependen de la perspectiva simpatético-imparcial, en cuanto el espectador imparcial regula el resentimiento espontáneo que todos los seres humanos sentimos al presenciar una agresión. De aquí que cuando los intérpretes afirman que la TMS no puede dar cuenta de normas universales porque el espectador imparcial se enraíza en lo empírico, no reparan en que Smith da vuelta el concepto moderno de universalidad, manteniendo, eso sí, las características moralmente relevantes del mismo: precisión, rango de aplicabilidad y fuerza vinculante. La única diferencia entre la noción de Smith y la comprensión moderna de las "reglas universales de justicia" es que en Smith ellas no dependen de principios trascendentes ni externos. Smith encontró una solución a la aporía de Anscombe. No busca principios prácticos supremos para validar los juicios morales, sino que los descubre en nuestros sentimientos morales naturales.

Así, cuando Griswold dice que la ética de Smith es esencialmente empírica y entonces incapaz de universalidad (1999, p. 94), está todavía pensando dentro del marco de la oposición moderna entre lo empírico y lo universal. Pero ese es el marco que Smith elimina. Su idea de universalidad o de autoridad universal de las reglas de justicia no pretende ser análoga al imperativo categórico, un principio fuera del espacio y el tiempo. Smith encontró la universalidad (entendida como normas válidas en todos los casos sin excepción) en el "tipo de ser que somos", en nuestros impulsos psicológicos innatos y nuestra capacidad para canalizarlos y modular nuestras disposiciones. Las "sagradas reglas de justicia" de la TMS no están fuera del espacio y el tiempo sino, idealmente, en todos los espacios y tiempos: surgen de las relaciones humanas en cualquier cultura posible. 


\section{RESPETO DE RECONOCIMIENTO, INMORALIDAD Y EXCELENCIA}

En una famosa analogía, Smith dice que las reglas de justicia son como las de la gramática, precisas e indispensables para la inteligibilidad de un texto; mientras que las de las virtudes positivas son como las de retórica: generales, orientativas, que presentan una idea de la perfección pero no proporcionan instrucciones infalibles ni son condición para comunicar ideas (TMS III.6.11). Ambas clases de normas, sin embargo, son reglas del discurso y una bella composición debe seguir las dos.

Al final del libro Smith repite la analogía pero ahora respecto de teorías morales: la ética de la virtud y las teorías de reglas de justicia. Smith rechaza el reduccionismo metodológico de ambos sistemas. Pero como buen observador de la naturaleza humana nota que una persona virtuosa integra gramática y retórica en su conducta, o virtudes negativas y positivas. También percibe que quienes se ajustan solo a la justicia quizás no son elogiables, pero tampoco dignos de condena; como en cambio sí lo son quienes no cumplen con la justicia. Vale decir, las virtudes positivas son deseables aunque no obligatorias. La justicia, en cambio, debe ser forzada: Sin gramática no hay inteligibilidad. No obstante, una teoría moral completa debe dar cuenta de ambos tipos de virtudes, distinguiendo sus tipos de reglas, precisión y fuerza vinculante.

Smith reconcilia la aspiración a la excelencia de los antiguos con los imperativos mínimos de los modernos a través del cambio de perspectiva moral. La perspectiva simpatético-imparcial permite distinguir tipos de importes y, con ello, tipos de normas. Desde el punto de vista de un espectador imparcial, todos somos conscientes del igual respeto que mutuamente nos debemos, y sentimos resentimiento inmediato cuando se trata a un igual como un inferior. De ahí las reglas mínimas de justicia que, por salvaguardar la igualdad, son obligatorias, precisas y universales. Esto es, son funcionalmente similares a los principios modernos que marcan un límite claro entre lo moral y lo inmoral. Pero en la TMS estas reglas no se respetan por su utilidad o racionalidad, sino porque fluyen naturalmente de los sentimientos morales, porque todo ser humano, dado el tipo de ser que es, se siente obligado a respetarlas.

Desde la perspectiva simpatético-imparcial también se aprehenden grados de excelencia en la virtud. Las pasiones/acciones pueden ser más o menos apropiadas para sus contextos particulares. La justicia, como el mínimo, casi no merece gratitud (TMS II.ii.1.9); la prudencia da lugar a una "fría 
estima" (TMS VI.1.14), mientras que la benevolencia provoca un "el mayor grado de aprobación" (TMS VII.ii.1.15).

De este modo, por un lado, la TMS traza un límite preciso y universal entre lo moral y lo inmoral: hay cosas que no podemos hacer a la gente. Y por el otro, también sugiere, aunque no impone, ideales de excelencia. Los muestra, los promueve, pero no condena a quienes eligen otros fines dentro de la esfera de lo permisible.

Smith ofrece pero no obliga a seguir su ideal normativo, ya que - dice Forman-Barzilai (2010, p. 238) - no sería coherente con su liberalismo. Y esta es otra virtud de la TMS, pues aunque promociona una concepción determinada de excelencia moral, también determina un mínimo ético universal que garantiza a todas las personas la libertad de seguir o no este ideal. Se recomienda la virtud, pero se deja toda la esfera de lo permisible a las decisiones individuales. La TMS no exige perfección ni condena la imperfección; solo condena la inmoralidad: la falta de respeto a un igual. Permitir que cada persona decida cómo vivir su vida también es reconocerla y respetarla como un igual. Imponerle ideales que ella no ha elegido sería tratarla como un inferior, como un niño incapaz de decidir por sí mismo. El respeto de reconocimiento no solo implica evitar la injusticia, sino también respetar la libertad de elegir los fines que cada cual decida para su vida.

\section{Conclusión}

Anscombe denunció la incompatibilidad entre la ética de la virtud y las éticas modernas. Aunque tiene razón en cuanto a la estructura metaética de esos sistemas, ello no implica que las virtudes dependientes del contexto y las normas universales sean incompatibles per se. Adam Smith, con su perspectiva simpatético-imparcial, propone un marco teórico diferente, un "tercer paradigma”, que con una nueva justificación para las virtudes y una nueva comprensión de la autoridad universal de ciertas reglas puede articular, en un sistema único, estos dos aspectos de la ética: las dos mandíbulas requeridas para dar cuenta comprehensiva de nuestra conducta moral.

A diferencia de los antiguos Smith basa su teoría en la interacción; en una conciencia empíricamente engendrada que debe estar en constante formación a través del diálogo. La virtud en la TMS se determina en los procesos simpatéticos, se justifica por la igualdad de todos los seres humanos 
expresada en el respeto que mutuamente nos debemos; y su "medida" es la imparcialidad, un estándar que a diferencia de la recta razón aristotélica es accesible a todos. Y a diferencia de los sistemas modernos Smith entiende por "reglas universales de la moral" aquellas reglas que son válidas en todos los casos, sin excepción, pero no por su trascendencia o justificación a priori, sino porque tienen autoridad y deberían ser respetadas en todas las culturas humanas al margen de tiempo y lugar. Smith da vuelta los principios modernos. La justicia es un deber, una obligación, cuya fuerza vinculante no proviene de ninguna autoridad externa sino que surge de la comunidad, de nuestros sentimientos morales, de la reacción afectiva que necesariamente tenemos frente a determinadas situaciones debido al tipo de ser que somos.

CARRASCO, María Alejandra. Adam Smith's ethics: A conciliation of moral paradigms. Trans/form/ação, Marília, v. 39, n. 3, p.23-38, Jul./Set., 2016.

\begin{abstract}
In his Theory of Moral Sentiments, Adam Smith reconciles two moral paradigms that are usually considered incompatible: an ethics of virtue, with general guidelines and ideals of excellence, and an ethics with universal rules, which must be applied to all cases without exceptions. Smith makes this possible by shifting the perspective from which moral judgments are assessed to what I call the 'sympathetic-impartial' perspective, which stands for "the sympathetic feelings of an impartial and well-informed spectator". From this new standpoint, Smith is able to introduce some modern features into classic virtue ethics and provide a different justification for positive virtues, as well as to change the way 'universal norms or principles' are understood. Accordingly, Smith's theory accounts simultaneously, and within the same theoretical framework, for both ancient-like virtues and their ideals of excellence and for modern-like universal imperatives.
\end{abstract}

KEYWORDS: Adam Smith, ethics, virtues, justice, universality

\title{
REFERENCIAS
}

ANSCOMBE, G. E. M. Modern moral philosophy. Philosophy, v. 33, n. 124, p. 1-19, 1958.

DARWALL, S. Empathy, sympathy, care. Philosophical Studies, v. 89, n. 2, p. 261-282, 1998.

Sympathetic liberalism: recent work on Adam Smith. Philosophy and Public Affairs, v. 28, n. 2, p. 139-64, 1999.

The Second-person Standpoint: morality, respect and accountability. Cambridge: Harvard University Press, 2006. 
FLESCHACKER, S. Sympathy in Hume and Adam Smith: a contrast, critique and reconstruction. In: FRICKE, C.; FOLLESDAL, D. (Ed.). Intersubjectivity and objectivity in Adam Smith and Edmund Husserl. Frankfurt: Ontos, 2012. p. 273-311.

FLEW, A. A dictionary of philosophy. 2nd. revised. New York: St. Martin's, 1984.

FORMAN-BARZILAI, F. Adam Smith on "connexion", culture and judgment. In: MONTES, L.; SCHLIESSER, E. New voices on Adam Smith. London: Routledge, 2006. p. $90-114$.

Adam Smith and the circles of sympathy: cosmopolitanism and moral theory. Cambridge: Cambridge University Press, 2010.

FRICKE, C. Adam Smith: the sympathetic process and the origin and function of conscience. In: BERRY, C.; PAGANELLI, P.; SMITH, C. (Ed.). The Oxford handbook of Adam Smith. Oxford: Oxford University Press, 2013. p. 177-200.

GRISWOLD, C. Adam Smith and the virtues of enlightenment. New York: Cambridge University Press, 1999.

. Reply to my critics. Perspectives on Political Science, v. 30, n. 3, p. 163-167, 2001.

. On the incompleteness of Adam Smith's system. The Adam Smith Review, v. 2, p.

181-186, 2006.

HAAKONSSEN, K. The science of a legislator. Cambridge: Cambridge University Press, 1981.

IRWIN, T. The development of ethics. New York: Oxford University Press, 2007.

KORSGAARD, C. The sources of normativity. Cambridge: Cambridge University Press, 1996.

SMITH, A. The theory of moral sentiments. Edited by D. D. RAPHAEL and A. L. MACFIE. Indianapolis: Liberty Fund, 1982.

STRAWSON, P. F. Freedom and resentment and other essays. London: Mathven, 1974.

TAYLOR, C. Self-interpreting animals. In: Human agency and language. New York: Cambridge University Press, 1985. p. 45-76.

TUGENDHAT, E. Universalistically approved intersubjective attitudes: Adam Smith. The Adam Smith Review, v. 1, p. 88-103, 2005.

Recebido em 20/11/2015

Aceito em 11/03/2016 